University of Nebraska - Lincoln

DigitalCommons@University of Nebraska - Lincoln

December 2007

\title{
Jhe in Gryllus assimilis: Cloning, sequence-activity associations and phylogeny
}

\author{
E. J. Crone \\ University of Nebraska - Lincoln
}

Anthony J. Zera

University of Nebraska - Lincoln, azera1@unl.edu

A. Anand

University of Nebraska - Lincoln

J. G. Oakeshott

CSIRO Entomology, Clunies Ross Street, Acton, ACT 2601, Australia

T. D. Sutherland

CSIRO Entomology, Clunies Ross Street, Acton, ACT 2601, Australia

See next page for additional authors

Follow this and additional works at: https://digitalcommons.unl.edu/bioscizera

Part of the Microbiology Commons

Crone, E. J.; Zera, Anthony J.; Anand, A.; Oakeshott, J. G.; Sutherland, T. D.; Russell, R. J.; Harshman, Lawrence G.; Hoffmann, Federico G.; and Claudianos, C., "Jhe in Gryllus assimilis: Cloning, sequenceactivity associations and phylogeny" (2007). Anthony Zera Publications. 27.

https://digitalcommons.unl.edu/bioscizera/27

This Article is brought to you for free and open access by the Papers in the Biological Sciences at DigitalCommons@University of Nebraska - Lincoln. It has been accepted for inclusion in Anthony Zera Publications by an authorized administrator of DigitalCommons@University of Nebraska - Lincoln. 


\section{Authors}

E. J. Crone, Anthony J. Zera, A. Anand, J. G. Oakeshott, T. D. Sutherland, R. J. Russell, Lawrence G. Harshman, Federico G. Hoffmann, and C. Claudianos 
Published in Insect Biochemistry and Molecular Biology 37:12 (December 2007), pp. 1359-1365; doi:10.1016/j.ibmb.2007.08.005

Copyright (C) 2007 Elsevier Ltd. Used by permission. http://www.sciencedirect.com/science/journal/09651748

Submitted November 20, 2006; revised August 12, 2007; accepted August 21, 2007; published online September 4, 2007.

\title{
Short Communication
}

\section{Jhe in Gryllus assimilis: Cloning, sequence-activity associations and phylogeny}

\author{
E. J. Crone ${ }^{\mathrm{a}}$, A. J. Zera ${ }^{\mathrm{a}, *}$, A. Anand ${ }^{\mathrm{a}}$, J. G. Oakeshott ${ }^{\mathrm{b}}$, T. D. Sutherland ${ }^{\mathrm{b}}$, R. J. Russell ${ }^{\mathrm{b}}$, \\ L. G. Harshman ${ }^{\text {a }, ~ F . ~ G . ~ H o f f m a n n ~}{ }^{\mathrm{a}}$ and C. Claudianos ${ }^{\mathrm{b}, \mathrm{c}}$ \\ ${ }^{a}$ School of Biological Sciences, University of Nebraska-Lincoln, Lincoln, NE 68588-0118, USA \\ ${ }^{\mathrm{b}}$ CSIRO Entomology, Clunies Ross Street, Acton, ACT 2601, Australia \\ ${ }^{c}$ Visual Neuroscience, Queensland Brain Institute, University of Queensland, St. Lucia, Brisbane, Qld 4072, Australia \\ * Corresponding author: tel. 402 472-2768; fax 402 472-2083; email azera1@unlnotes.unl.edu
}

\begin{abstract}
The 458 amino acid sequence of a mature JHE protein from the cricket Gryllus assimilis was identified after isolating the partial cDNA sequence encoding this protein from a fat body and midgut cDNA library. This hemimetabolan JHE sequence shows over $40 \%$ amino acid similarity to the known JHE sequences of several holometabolous insects. It also includes previously determined peptide sequences for G. assimilis JHE as well as two other motifs associated with JHE enzymes in holometabolous insects. The predicted molecular weight of the protein agrees with that of the JHE previously purified from G. assimilis. Partial genomic sequence encoding the Jhe contains two large (1330 and $2918 \mathrm{bp}$ ) introns. No coding DNA sequence variation was observed over a $1293 \mathrm{bp}$ region between selected lines differing six to eight-fold in hemolymph JHE activity. However, a 19 bp indel was found in one of the introns; the insertion was strongly associated with elevated hemolymph activity, both in the selected lines and in the $\mathrm{F}_{2}$ progeny of crosses between them. Phylogenetic analyses localised the G. assimilis JHE to a clade containing dipteran and coleopteran JHEs, with lepidopteran JHEs occurring in a separate clade.
\end{abstract}

Keywords: Juvenile hormone esterase gene, Gryllus assimilis, Hemimetabolous insect, Indel polymorphism, Phylogeny

\section{Introduction}

Juvenile hormone esterase (JHE) is an enzyme that hydrolyses and partially regulates the titre of juvenile hormone $(\mathrm{JH})$, a key developmental and reproductive hormone in insects. Because of its importance in endocrine regulation, JHE has been extensively studied from physiological, biochemical and molecular perspectives (Hammock, 1985; Goodman and Granger, 2005; Oakeshott et al., 2005). In a number of insects, especially lepidopterans, the purified JHE enzyme has been characterised kinetically and structurally, and the Jhe gene has been sequenced and its molecular regulation investigated (Hammock, 1985; Venkataraman et al., 1994; Oakeshott et al., 2005; Wogulis et al., 2006; Bai et al., 2007).

JHE also has been one of the most extensively studied insect endocrine regulators from an evolutionary genetic perspective, particularly in Gryllus crickets (Zera, 2006; Zera et al., 2007).
Thus far, these evolutionary genetic studies have focused exclusively on biochemical and physiological aspects of JHE.

Four hemolymph JHE isoforms were purified to homogeneity from the cricket Gryllus assimilis; these isoforms differed among themselves in up to four of 13-20 residues at the $\mathrm{N}$-terminus of the mature protein (Table 1; Zera et al., 2002). We used these amino acid sequences to design a probe that was used in a hybridisation screen of a $G$. assimilis fat body and midgut cDNA library. By these means, we recovered a presumptive Jhe gene. We show that this gene encodes a protein with diagnostic JHE sequence motifs, and that there is strong covariation between the sequence of an intron of this gene and hemolymph JHE enzyme activity in artificially selected lines of $G$. assimilis. Phylogenetic analysis indicates that the inferred protein product of the cloned gene sits within the same clade as dipteran and coleopteran JHEs, with lepidopteran JHEs lying in a separate clade. 
Table 1.

$\mathrm{N}$-terminal amino acid sequences of the isoforms of the mature JHE protein of G. assimilis reported in Zera et al. (2002)

\begin{tabular}{ll}
\hline Isoform & Sequence \\
\hline JHE-1 (minor) & AEAPD EVEKA xGx \\
& AEAAP EVEVA QKRMR AAAV \\
JHE-2 & AEADP EVEVA QxRMR GAVVP \\
JHE-3 & AEAAP EVEVA QKRMR AAVVP \\
JHE-4 (minor) &
\end{tabular}

(L)

" $\mathrm{x}$ " refers to an unidentified residue; letter in brackets indicates ambiguity in the identity of the amino acid at that site, which could be either the residue designated by the letter above the brackets or within the brackets; "minor" means that band intensity of the isoform was much less than the JHE-2 and JHE-3 isoforms on an IEF gel (see Figure 4 of Zera et al., 2002).

\section{Materials and methods}

Mass-reared lines of $G$. assimilis previously selected for high or low hemolymph JHE activity (differing six to eightfold in JHE activity; Zera and Zhang, 1995; Zera, 2006), or maintained as unselected controls, were used in the present study. JHE had been previously purified to homogeneity and characterised from the high activity and control lines (Zera et al., 2002). In the current study, a cDNA library from $G$. assimilis was constructed from fat body and midgut tissues taken from a mixture of 50 mid-last stadium (days 47, post moult) individuals from high activity, low activity and unselected control lines. Inbred lines used in pair crosses were produced from the mass-selected high and low activity lines by five generations of brother-sister mating. Crickets were reared, staged and hemolymph obtained as in previous studies (Zera and Zhang, 1995). JHIII hydrolytic activity was tested routinely using the standard radiochemical assay of Hammock and Sparks as applied to G. assimilis (Zera and Zhang, 1995).

To construct a cDNA library from $G$. assimilis, total RNA, and subsequently mRNA, were isolated using the Totally RNA isolation kit (Ambion, Austin, TX) as per the manufacturer's instructions. A combined random and oligo(dT) primed cDNA library was made by Clontech (Palo Alto, CA). The cDNA library was initially screened by PCR to verify that a Jhe cDNA was contained within it, and to obtain an amplicon that could be used for further library screening. Degenerate oligonucleotides (5'-CNGARGCNGCICCNGARGT3', 5'-GCNGCICKCATNCKYTTYTG-3') (nomenclature as per Sambrook et al., 1989) that bracketed the ends of a 20 amino acid sequence of the N-terminus of one isoform (JHE3) of the mature JHE protein (Table 1; Zera et al., 2002) were used to initially screen $\sim 10^{3}$ pfu $(1 \mu \mathrm{l})$ of the unamplified library. The PCR reactions were performed in $50 \mu \mathrm{l}$ and contained the following final concentrations: $1 \times$ PCR buffer, $1.5 \mathrm{mM} \mathrm{MgCl}_{2}, 2 \mathrm{mM}$ each dNTP, $0.25 \mu \mathrm{M}$ each primer and
0.5 units Taq DNA polymerase (Invitrogen, Carlsbad, CA). PCR cycles comprised an initial denaturation step of $5 \mathrm{~min}$ at $94{ }^{\circ} \mathrm{C}$, followed by 35 cycles of $94{ }^{\circ} \mathrm{C}$ for $30 \mathrm{~s}, 50{ }^{\circ} \mathrm{C}$ for $30 \mathrm{~s}$ and $72^{\circ} \mathrm{C}$ for $3 \mathrm{~s}$, and a final extension step of $7 \mathrm{~min}$ at $72{ }^{\circ} \mathrm{C}$. An amplicon of expected size was sequenced using BigDye terminator sequencing (Applied Biosystems, Foster City, CA).

A highly degenerate probe based on the amplicon obtained in the initial library screen (5'-CWGARGCIGCGCCIGARGTSGARGTIGTICARAARMGIATGMGCGCIGC$\left.3^{\prime}\right)$ was used to subsequently screen $210,000 \mathrm{pfu}$ of the unamplified cDNA library according to the manufacturer's instructions (Clontech, Palo Alta, CA). A single positive plaque that hybridised was purified and converted to a pTriplEx clone (according to manufacturer's instructions, Clontech, Palo Alta, CA) and sequenced as above.

Rapid amplification of cDNA ends (RACE) was used to amplify the 3 '-end of the Jhe cDNA. Total RNA was isolated from the head and thorax of a single $G$. assimilis adult using the SV Total RNA Isolation System (Promega, Madison, WI). 3'-RACE was performed using the 3'-RACE System for Rapid Amplification of cDNA Ends (Invitrogen, Carlsbad, CA) with the gene specific oligonucleotides: 3'-GSP1.602U (5'-TGTCGCCGCTCTCCAAAGGT-3') and 3'-GSP2.1292U (5'-TCTTCGGCGGCGGGCTCAAC-3'). The amplicon was cloned into the pGem-T Easy vector (Promega, Madison, WI) and sequenced as above. Attempts to amplify the 5'-end of the cDNA (i.e., encoding the untranslated leader and the codons for the presumptive signal peptide) using 5'-RACE were unsuccessful.

Genomic DNA, used to amplify Jhe introns by PCR, was extracted from the head and hind legs of a cricket from a line previously selected for high hemolymph JHE activity and a cricket from a line selected for low hemolymph JHE activity (Zera and Zhang, 1995) as follows: tissues were homogenised in cold 0.1 M Tris ( $\mathrm{pH}$ 9), $0.1 \mathrm{M}$ EDTA using a glass tube pestle, after which an equal volume of $2 \%$ SDS (w/v) solution was added. Samples were then incubated at $65^{\circ} \mathrm{C}$ for $1 \mathrm{~h}$, cooled to room temperature, and $0.86 \mathrm{M}$ potassium acetate $(8 \mathrm{M})$ added to each tube to precipitate proteins. After incubation on ice for $30 \mathrm{~min}$, samples were centrifuged for $20 \mathrm{~min}$ at $16,000 \times g$. The supernatant was extracted once with an equal volume of phenol, then once with 0.5 volume of phenol and chloroform. Samples were treated with $10 \mu \mathrm{g}$ RNase (Sigma, St. Louis, MO) at $37^{\circ} \mathrm{C}$ for $20 \mathrm{~min}$, then with $10 \mu \mathrm{g}$ of Proteinase K (Invitrogen, Carlsbad, CA) at $37^{\circ} \mathrm{C}$ for $20 \mathrm{~min}$. Samples were again extracted with 0.5 volume of phenol/ chloroform, and DNA was precipitated with 0.4 volume isopropanol for $10 \mathrm{~min}$ at room temperature and collected after centrifugation at $16,000 \times g$ for $10 \mathrm{~min}$. The DNA pellets were washed twice with $70 \%(\mathrm{v} / \mathrm{v})$ ethanol and resuspended in $10 \mathrm{mM}$ Tris ( $\mathrm{pH} \mathrm{8),} 1 \mathrm{mM}$ EDTA.

Oligonucleotides designed to different regions of the Jhe cDNA sequence were used to screen $G$. assimilis genomic DNA for introns. The oligonucleotide GaJHE1160U [5'-CCGGAGCTCATGGAGTTGGA-3', cDNA (Figure 1) co-ordi- 
nates 1036-1055) was coupled with either GaJHE1249L (5'cggtaggccatctcgtagac-3', cDNA co-ordinates 1249-1268) or GaJHE1306L (5'-ACACGCCGTAGTCGTTGAG-3', cDNA co-ordinates 1306-1324]. PCR reactions contained 60-70 ng genomic DNA in $50 \mu \mathrm{l}$ with final concentrations of the following: $60-70 \mathrm{ng}$ genomic DNA, $1 \times \mathrm{PCR}$ buffer, $1 \mathrm{mM} \mathrm{MgCl}$, $0.2 \mathrm{mM}$ each dNTP (Invitrogen, Carlsbad, CA), $0.2 \mu \mathrm{M}$ each primer, 2.5\% (v/v) DMSO (Sigma, St. Louis, MO) and $1 \mathrm{U}$ Taq DNA polymerase (BullsEye, MidSci, St. Louis, MO; or Taq DNA polymerase, Invitrogen, Carlsbad, CA). PCR cycles comprised an initial denaturation step of $2 \mathrm{~min}$ at $94^{\circ} \mathrm{C}$, followed by 30 cycles of $94{ }^{\circ} \mathrm{C}$ for $30 \mathrm{~s}, 52^{\circ} \mathrm{C}$ for $30 \mathrm{~s}$ and $72{ }^{\circ} \mathrm{C}$ for $2 \mathrm{~min}$, and a final extension step of $7 \mathrm{~min}$ at $72{ }^{\circ} \mathrm{C}$. The oligonucleotide gwalker79U (5'-ATCTACGCCTTCCGCAGCATCCCGTTC-3', cDNA co-ordinates 79-105) was coupled with gwalker205 (5'-GTACGGCGGCACCAAGTAGTTCTTCTG-3', cDNA co-ordinates 205-231) in $50 \mu \mathrm{l}$ reactions containing the same final concentrations as above. PCR cycles comprised seven cycles of $94{ }^{\circ} \mathrm{C}$ for $25 \mathrm{~s}, 72{ }^{\circ} \mathrm{C}$ for 3 min followed by 30 cycles of $94{ }^{\circ} \mathrm{C}$ for $25 \mathrm{~s}, 67^{\circ} \mathrm{C}$ for $3 \mathrm{~min}$ and a final extension step of $7 \mathrm{~min}$ at $67^{\circ} \mathrm{C}$. The PCR reactions were purified using the QIAquick PCR purification kit (QIAgen, Valencia, CA) and cloned into the pGem-T Easy vector following manufacturer's directions (Promega, Madison, WI). Clones were sequenced as above.

Routine rapid screening of crickets for a $19 \mathrm{bp}$ insertion/ deletion (the $J h e^{\mathrm{L} / \mathrm{S}}$ indel) within an intron was performed using genomic DNA extracted from one hind leg using Chelex DNA Extraction. In brief, each leg was homogenised in a $1.5 \mathrm{ml}$ centrifuge tube, using a motor-driven pestle, in a total of $207 \mu \mathrm{l}$ containing $0.01 \mathrm{~g}$ Chelex 100 Resin (BioRad, Hercules, CA), $0.02 \mathrm{mg}$ Proteinase K (Invitrogen, Carlsbad, CA), $0.34 \mathrm{M}$ dithiothreitol (DTT; Sigma-Aldrich, St. Louis, MO). The homogenates were incubated at $56{ }^{\circ} \mathrm{C}$ for $1 \mathrm{~h}, 95^{\circ} \mathrm{C}$ for $10 \mathrm{~min}$, vortexed for $15 \mathrm{~s}$, centrifuged at $14,000 \times \mathrm{g}$ for $1 \mathrm{~min}$, and the supernatant was removed. The supernatant was diluted $1 / 10$ and $1 \mu \mathrm{l}$ was used as template for PCR. Each PCR reaction was performed in a total of $50 \mu$ and contained the following final concentrations: $1 \times \mathrm{PCR}$ buffer, $1 \mathrm{mM} \mathrm{MgCl} 2$, $0.2 \mathrm{mM}$ each dNTP (Invitrogen, Carlsbad, CA), 2.5\% (v/ v) DMSO (Sigma, St. Louis, MO) $0.2 \mu \mathrm{M}$ each primer [ $3^{\prime}-$ in181U 5'-CACCCCACTTATCGCTTCAT-3', EU0579709

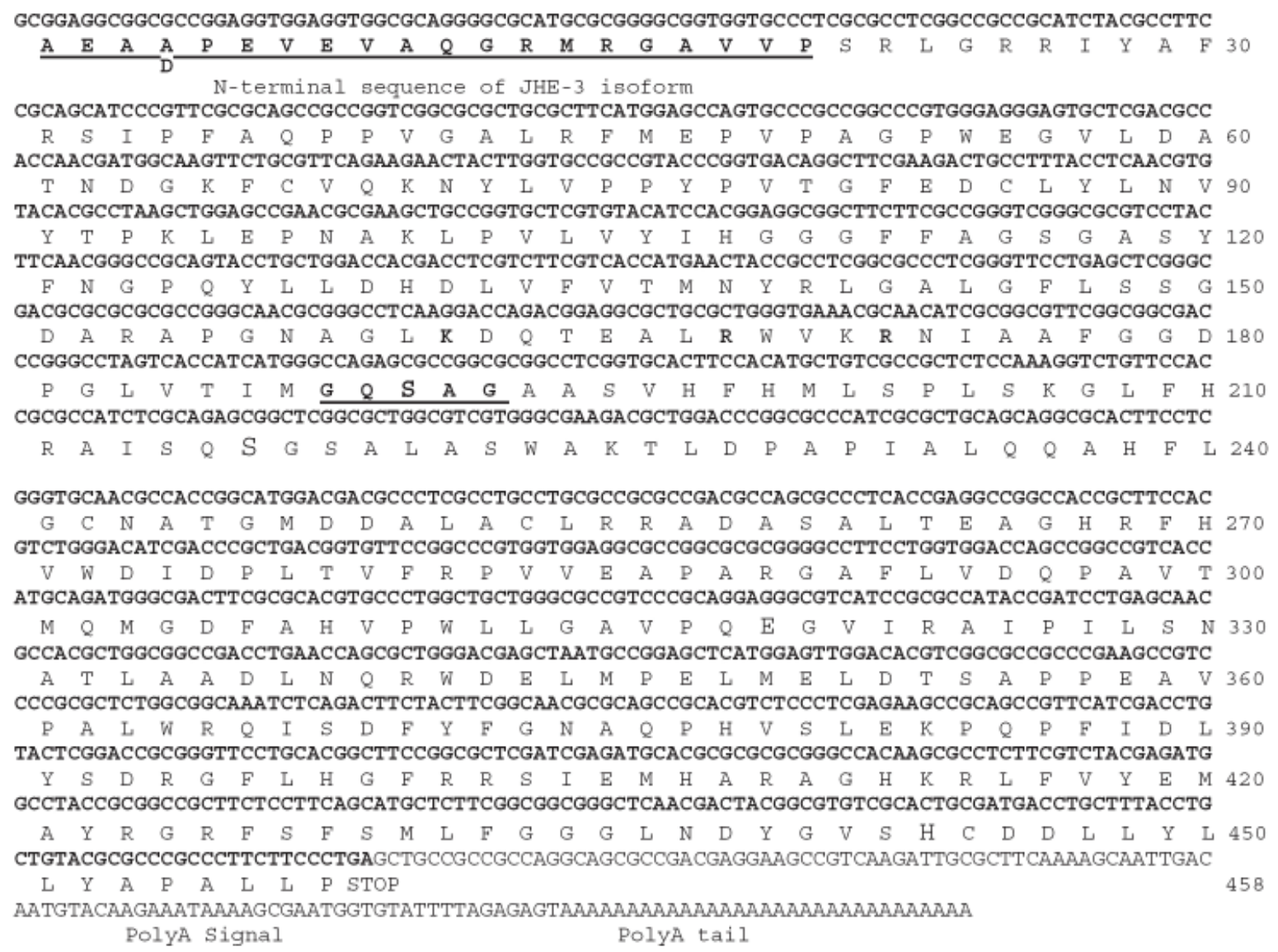

Figure 1. Nucleotide sequence and amino acid translation of G. assimilis Jhe cDNA (Genbank accession no. EF558769). The residues which make up the 20 amino acid N-terminal sequence of the mature protein are in bold type face and underlined. With one exception (alanine at position four compared to an aspartic acid), the translated amino acid sequence corresponds to the amino acid sequence of the previously reported JHE-3 isoform (Zera et al., 2002). The GQSAG motif, which is an uncommon variant of the general esterase active site motif GXSXG, but which is found in all known JHEs, is in bold type face and underlined. The three amino acids that comprise the amphipathic helix also are in bold type face. 
(see Section 3) co-ordinates 1762-1781; GaJint.259L 5'CTTGGTGTGGCGTGTGTAAC-3', EU057970 coordinate 1953-1972); and 1U Taq DNA polymerase (BullsEye from MidSci, St. Louis, MO; or native Taq DNA polymerase from Invitrogen, Carlsbad, CA). The PCR protocol comprised an initial denaturation step of $2 \mathrm{~min}$ at $94^{\circ} \mathrm{C}$; followed by 35 cycles of $94{ }^{\circ} \mathrm{C}$ for $30 \mathrm{~s}, 51{ }^{\circ} \mathrm{C}$ for $30 \mathrm{~s}, 72{ }^{\circ} \mathrm{C}$ for $30 \mathrm{~s}$; and a final extension step of $72{ }^{\circ} \mathrm{C}$ for $7 \mathrm{~min}$ and $25^{\circ} \mathrm{C}$ for $30 \mathrm{~s}$. PCR products were separated on a $4 \%(w / v)$ agarose gel with $1 \times$ TAE buffer. DNA banding patterns were visualised using ethidium bromide.

To determine whether the JHE coding sequence differs between crickets selected for high or low hemolyph JHE activity, total RNA was isolated individually from four high activity and four low activity $G$. assimilis using Trizol (Invitrogen). RNA was treated with DNAase, converted into cDNA using 200u SuperScript II (Invitrogen, Carlsbad, CA) and an oligo(dT18) primer following manufacturers instructions. JHE amplicons were produced using the following primers: gwalker79U (sequence given above; cDNA co-ordinates 79105) and GaJHE1348 (5'-GAAGAAGGGCGGGCGCGTACAG-3'; cDNA co-ordinates 1350-1372 bp). PCR conditions were the same as those described above using gwalker79U, except that the $72 \mathrm{C}$ extension step was $1 \mathrm{~min}$. Amplicons were cloned into the pGen-T Easy vector and sequenced as described above.

Phylogenetic analyses were conducted using NeighborJoining (Felsenstein, 2004) and Maximum Likelihood methods (Felsenstein, 2004) to determine the relationships among $G$. assimilis JHE and other JHEs. The analysis was performed on the data set that included sequences for JHEs and catalytically active carboxyl/choline esterases reported in Claudianos et al. (2006), JHE for G. assimilis (this study), and several JHE and carboxyl/cholinesterase sequences reported subsequent to the study of Claudianos et al. (2006) (see legend of Figure 3). The amino acid sequence alignment was performed using MUSCLE multiple alignment software (Edgar, 2004), and phylogenetic analyses were conducted in MEGA3 (Kumar, et al., 2004).

\section{Results and discussion}

A cDNA library from $G$. assimilis was constructed using mid-last-stadium fat body and midgut tissues, two tissues that contain high JHE activity in this (Zera, unpublished data), and other insect species (e.g., Bai et al., 2007). Previously, two major and two minor JHE isoforms were found in G. assimilis, which differ by one to several amino acids at the N-terminus of the mature protein (Table 1; Zera et al., 2002). Degenerate primers were designed to the 3 '- and 5 '-ends of one of these sequences (JHE-3). The presence of Jhe cDNA in the cDNA library from $G$. assimilis was established by the finding of PCR amplicons which contained the diagnostic nucleotide sequence encoding three amino acids in the middle of the known peptide sequence that were not encoded by the oligonucleotide primers. The library was then screened by hybri- disation using a degenerate probe based on the amplified sequence. A single partial cDNA clone of $1445 \mathrm{bp}$ that did not contain start codons, and which contained diagnostic JHE motifs, was identified. The 5 '-end of the clone encoded the N-terminal sequence of the JHE-3 major isoform of the mature JHE protein (Table 1; Zera et al., 2002), but with an alanine rather than aspartic acid in the fourth position. Two of the other three JHE isoforms, JHE-2 and JHE-4, also contained alanine in this position (Table 1; Zera et al., 2002).

The 3'-end of the $G$. assimilis Jhe cDNA was obtained using RACE. Attempts to obtain additional 5'-sequence by RACE and inverse PCR (data not shown) were unsuccessful suggesting that there may be significant secondary structure in this region. The additional $67 \mathrm{bp}$ of sequence generated by the 3 -RACE, together with the original cloned cDNA provided a total of $1512 \mathrm{bp}$ of cDNA sequence which begins at the codons specifying the residues at the N-terminus of the mature protein determined earlier (Zera et al., 2002) and ends in a 3'-untranslated sequence and polyadenylated tail (GenBank accession no. EF558769). The mature protein encoded by this gene has a predicted molecular weight of $50 \mathrm{kDa}$, which corresponds to the subunit molecular weight determined for the mature protein $(52 \mathrm{kDa}$; Figure 1; Zera et al., 2002).

The protein sequence has $51 \%$ similarity to the JHE of the cerambycid beetle Psacothea hilaris, 49\% similarity to Drosophila melanogaster JHE and $45 \%$ similarity to Heliothis virescens JHE. The G. assimilis JHE contained two particular sequence features which are found in all known JHEs to date (Figure 1; see Oakeshott et al., 2005 and references therein). The first of these is a GQSAG motif around the serine residue of the catalytic triad, which is an uncommon variant of the general esterase active site motif (GXSXG). The second of these is a predicted amphipathic helix about 18-29 amino acids upstream of the catalytic serine triad residue which has three or four basic residues along one face.

No differences in $1293 \mathrm{bp}$ of the Jhe coding sequence were observed among eight amplicons each of which had been derived from a different $G$. assimilis (four from a high activity line, four from a low activity line). This result suggests that line differences in JHE activity are not due to allelic differences in catalytic efficiency, at least for the Jhe gene isolated in the present study. This finding is consistent with a previous analysis of $G$. assimilis hemolymph JHE, which did not identify any kinetic difference between enzymes from these high and low activity lines (Zera, 2006). High and low activity lines differ in JHE transcript abundance (Crone, Zera and Anand; unpublished data), implicating variation in Jhe gene expression as a cause of activity differences between selected lines.

Two introns within the Jhe gene were located at 138 and $1167 \mathrm{bp}$ (cDNA numbering), and were 1131 and $2918 \mathrm{bp}$ in length, respectively; both contained a variant of the Drosophila exon/intron splice recognition sequence (Drosophila splice donor $\mathrm{A}_{69} \mathrm{G}_{59}$ (exon) $\left[\mathrm{G}_{100} \mathrm{~T}_{100} \mathrm{~A}_{55} \mathrm{~A}_{81} \mathrm{G}_{84} \mathrm{~T}_{68}\right.$ (intron)/ splice acceptor $\mathrm{C}_{76} \mathrm{~A}_{97} \mathrm{G}_{100}$ (intron)] (exon)). Only seven sin- 
gle nucleotides differed between the selected lines in the intron at $139 \mathrm{bp}$, while a $19 \mathrm{bp}$ insertion/deletion polymorphism (5'-GTCGGCCCCAATCCGCTCT-3'; indel sequence found $187 \mathrm{bp}$ from start of intron) was observed in the other intron (partial genomic DNA sequence GenBank accesion no. EU057970).

To determine whether the frequency of the $19 \mathrm{bp}$ indel within the 3'-intron differed between the lines of G. assimilis selected for high or low hemolymph JHE activity, a fast screening method was developed using genomic DNA isolated from one hind leg of a cricket, PCR amplification, and visualisation by agarose gel electrophoresis (Figure 2). The frequency of $J h e^{\mathrm{L}}$ (insertion) in a high JHE activity line was $0.91(n=32)$, while the frequency of this insertion in a low activity line was $0.00(n=27)$.

To more firmly establish the extent of association between JHE hemolymph activity and indel phenotype, pair crosses were performed between inbred lines derived from the high or low JHE activity lines. An individual from a high JHE activity inbred line homozygous for $J h e^{\mathrm{L}}$ was crossed with an individual from a low activity inbred line homozygous for $J h e^{\mathrm{S}}$. This cross was replicated using another pair of parents from a different set of lines. Individual $F_{1}$ progeny from each cross were then pair-crossed and hemolymph JHE activity and indel phenotype (electrophoretic band size) were measured in the $F_{2}$ progeny. JHE activities (mid-last stadium; day 4-5 post moult) did not differ between the same indel phenotypes in $\mathrm{F}_{2}$ progeny of the two crosses, and thus data for the two crosses were pooled. The indel phenotypes differed substantially in JHE activity $(P<0.008$, one-way ANOVA). Individuals homozygous for the $J h e^{\mathrm{L}}$ indel $\left(J h e^{\mathrm{LL}}, n=13\right)$ had significantly higher JHE hemolymph activity $(31.8 \pm 2.7 \mathrm{nmol} \mathrm{JHIII}$ acid $/ \mathrm{min} / \mathrm{ml})$ than either heterozygous individuals $(24.1 \pm 1.9 \mathrm{nmol} \mathrm{JHIII}$ acid/ $\mathrm{min} / \mathrm{ml}$; Jhe $e^{\mathrm{LS}}, n=22 ; p<0.05$ ) or individuals homozygous for the $J h e^{\mathrm{S}}$ indel $\left(20.5 \pm 2.4 \mathrm{nmol} \mathrm{JHIII} \mathrm{acid} / \mathrm{min} / \mathrm{ml} ; J h e^{\mathrm{SS}}, n=16\right.$; $p<0.005)$. In other words, hemolymph JHE activity and indel phenotype co-segregated strongly in the $\mathrm{F}_{2}$ progeny.

This strong co-segregation between the indel phenotype and JHE activity does not formally prove that the cDNA cloned in this study encodes a physiological JHE enzyme. What it shows is that the cloned gene is at least very closely linked genetically to the source of the activity variation. In view of the four esterase isoforms with JHE activity in vitro that Zera et al. (2002) obtained from G. assimilis, it would be plausible to suggest that there are multiple closely linked Jhe or Jhe-like genes in this species. Importantly, however, there is also evidence for parallel differences in the abundance of transcript encoded by the cloned Jhe gene between the high and low selected JHE lines (Crone, Zera and Anand, unpublished data). Given also its possession of the diagnostic JHE sequence motifs and the co-segregation of indel and activity variation observed here, we conclude that the Jhe gene described here is, at the least, a significant contributor to physiological JHE activity.

Results of the phylogenetic analysis (Figure 3) placed JHE from $G$. assimilis within the clade containing JHEs from cole- opterans and dipterans with very strong support ( $99 / 85 \%$ bootstrap). This clade did not include lepidopteran JHEs, which all clustered on a separate branch of the tree with strong support (99/100\% bootstrap), in agreement with the tree presented by Claudianos et al. (2006). The tree in Figure 3 provides support for the hypothesis forwarded by Claudianos et al. (2006) that there are two separate origins of JHE in the insect esterases.

To more formally test the hypothesis of multiple vs. single origin of JHEs, the likelihood scores were compared for the tree presented in Figure 3 (consistent with two independent origins of JHE), compared with a tree where JHEs were forced into a monophyletic clade (constructed using Treefinder (Jobb et al., 2004). The multiple-origin tree $(-\ln L=-76912.2)$ was significantly better supported $(p<0.002)$ than the single-origin tree $(-\ln L=-77142.5)$ in a Shimodaira-Hasegawa topology test (see Jobb et al., 2004).

The close clustering between JHEs from G. assimilis and Tenebrio molitor is consistent with biochemical data. For example, G. assimilis JHE exclusively exists as dimer while $T$. molitor JHE exists as a partial dimer (Hinton and Hammock, 2003). All other insect JHEs are reported to be monomers (Zera et al., 2002). At present, the esterase tree is not well enough resolved to determine which JHE clade is ancestral.

Other lines of evidence suggest that there may be more than two independent origins of JHE in insects. In the honey bee Apis mellifera there are two candidate Jhe genes (Claudianos et al., 2006), which sit in different clades, both from

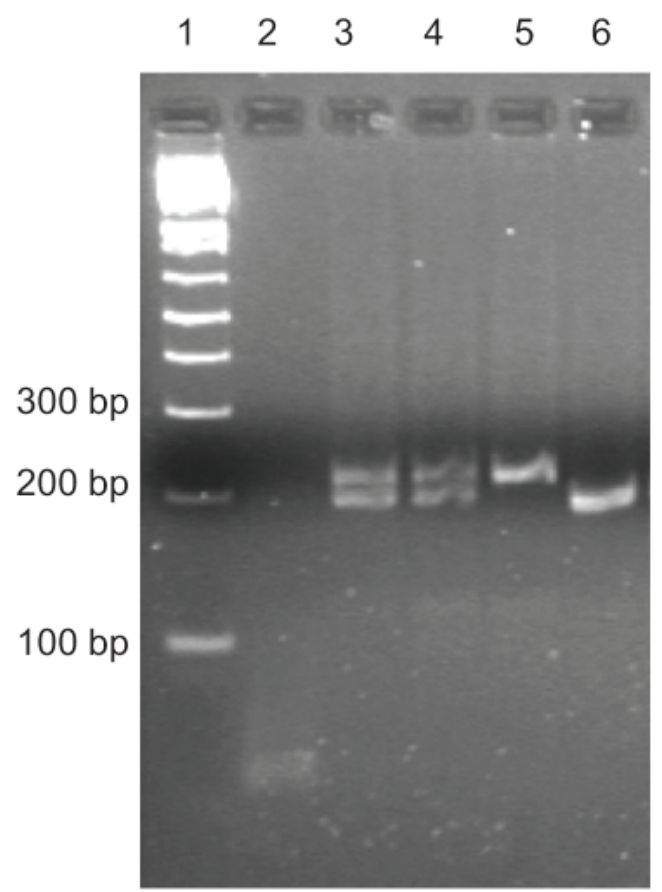

Figure 2. Agarose gel showing separation of amplicons containing an insertion/deletion polymorphism within the 3 '-intron of the Jhe gene of G. assimilis. Lane 1, 1Kb PLUS DNA ladder (Invitrogen, Carlsbad, CA); lane 2, no template control reaction; lanes 3 and 4, show heterozygous individuals $\left(J h e^{\mathrm{L} / \mathrm{S}}\right)$; lane 5 , homozygous individual for $J h e^{\mathrm{L} / \mathrm{L}}$; lane 6, individual homozygous for $J h e^{\mathrm{S} / \mathrm{S}} . J h e^{\mathrm{L}}=191 \mathrm{bp}$; Jhe $e^{\mathrm{S}}=172 \mathrm{bp}$. 


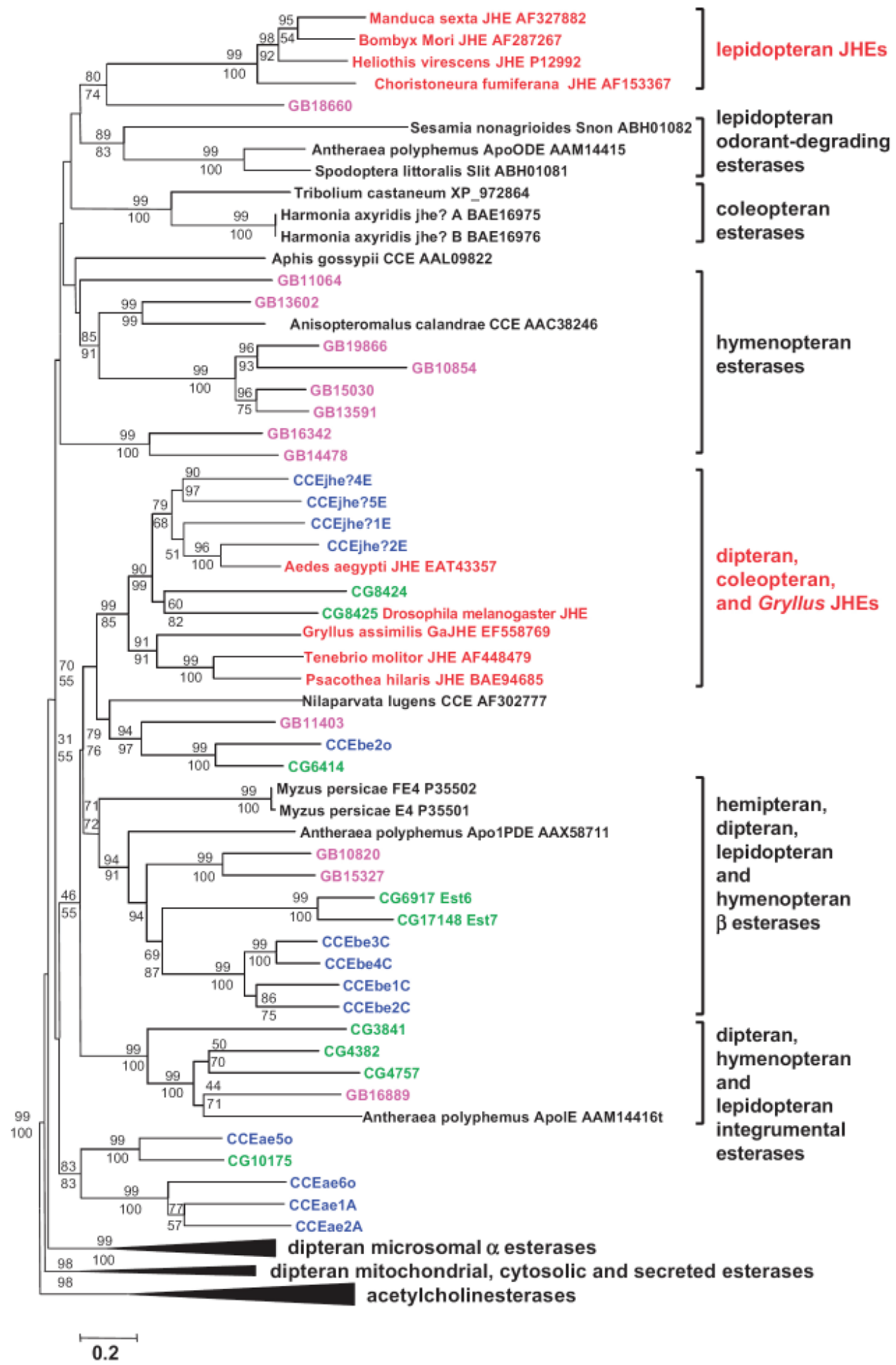

Figure 3. Evolutionary relationships of JHEs and other insect carboxyl/cholinesterases. The tree was obtained by applying the Neighbor-Joining method (Saitou and Nei, 1987; cited in Felsenstein, 2004) to the alignment of catalytic carboxyl/cholinesterases in Claudianos et al. (2006) updated with the G. assimilis sequence from the present paper; JHE sequences from Hinton and Hammock (2003), Merlin et al. (2007), Munyiri and Ishikawa (2007), Bai et al. (2007); and recent Genbank entries for one Tribolium castaneum and two Harmonia axyridis esterases. The optimal tree with the sum of branch length=47.968 is shown. Some large clades have been collapsed. For ease of viewing, all JHE sequences are coloured in red. In addition, Drosophila melanogaster (green), Anopheles gambiae (blue) and A. mellifera (magenta) sequences have also been colour-coded. The tree is drawn to scale, with branch lengths in the same units as those of the evolutionary distances used to produce it. Distances were computed using the Dayhoff matrix-based method and the units are the number of amino acid substitutions per site. Positions containing alignment gaps and missing data were only eliminated in pairwise sequence comparisons (pairwise deletion option). There were a total of 598 positions in the final dataset. A Maximum Likelihood analysis (Felsenstein, 2004) produced a tree with topology congruent with this Distance-based tree. The percentages of replicate trees in which sister groups clustered together in the bootstrap test in $>50 \%$ of 1000 replicates (Felsenstein, 2004) are shown for both the Distance and Maximum Likelihood (normal font and italicised, respectively) analyses. Note that six sequences in the tree are shown as 'jhe?' because we have been unable to find published evidence that they encode functional JHEs; the two H. axyridis sequences were annotated as JHEs in their Genbank entries while the four A. gambiae sequences were simply annotated as candidate JHEs by Ranson et al. (2002; cited in Claudianos et al., 2006) on the basis of their sister group status with the known D. melanogaster JHE. These six 'jhe?' sequences were not included in the maximum liklihood test of multiple vs. single origin of JHEs described in the text. 
each other and from the lepidopteran and dipteran/coleopteran JHEs. Several D. melanogaster carboxylesterases have measurable JHE activity in vitro (Crone et al., 2007) further suggesting the potential for repeated JHE evolution from carboxylesterases. With respect to enzyme structure, it may not have been a major evolutionary challenge to evolve physiological levels of JHE activity from a range of potential carboxylesterase starting points: JH is a sesquiterpenoid ester of methanol and as such has a long acyl group but a very small alcohol group. Because the long acyl group can be accommodated along the length of the active site gorge, with little extra space needed at the base of the gorge to accommodate the alcohol moiety, carboxylesterases may not require a highly elaborated pocket structure in their active site to accommodate $\mathrm{JH}$ productively (Wogulis et al., 2006).

Isolation of this hemimetabolan cDNA will allow a broader understanding of basic molecular aspects of Jhe structure, regulation and phylogeny in insects. The G. assimilis Jhe indel polymorphism that strongly co-segregated with JHE hemolymph activity also will be useful in studies examining the molecular causes of JHE activity variation in natural populations. Such studies will be particularly important since the molecular basis of naturally occurring endocrine variation in insects is poorly understood (Zera, 2006; Zera et al., 2007).

\section{Acknowledgments}

This research was supported by grant IBN-0212486 (National Science Foundation, USA) to A.J.Z., L.G.H. and J.G.O. We thank two undergraduate researchers for excellent technical assistance in screening the crickets for the Jhe indel, Mallary Hoidal and Joanna Lubberts.

\section{References}

BAI ET AL., 2007 - H. Bai, P. Ramaseshadri, and S. R. Palli, Identification and characterization of juvenile hormone esterase gene from the yellow fever mosquito, Aedes aegypti, Insect Biochem. Mol. Biol. 37 (2007), pp. 829-837.

Claudianos ET AL., 2006 - C. Claudianos, H. Ranson, R. M. Johnson, S. Biswas, M. A. Schuler, M. R. Berenbaum, R. Feyereisen, and J. G. Oakeshott, A deficit of detoxification enzymes: pesticide sensitivity and environmental response in the honeybee, Insect Mol. Biol. 15 (5) (2006), pp. 615-644.

Crone et al., 2007 - E. J. Crone, T. D. Sutherland, P. M. Campbell, C. W. Coppin, R. J. Russell, and J. G. Oakeshott, Only one esterase of Drosophila melanogaster is likely to degrade juvenile hormone in vivo, Insect Biochem. Mol. Biol. 37 (2007), pp. 540-549.

EdGAR, 2004 - R. C. Edgar, MUSCLE: multiple sequence alignment with high accuracy and high throughput, Nucleic Acids Res. 32 (5) (2004), pp. 1792-1797.

Felsenstein, 2004 - J. Felsenstein, Inferring Phylogenies, Sunderland Associates, Sunderland, MA (2004).

Goodman and Granger, 2005 - W. G. Goodman and N. A. Granger, The juvenile hormones. In: L.I. Gilbert, K. Iatrou and S.S. Gill, Editors, Comprehensive Molecular Insect Science vol. 3, Elsevier, Boston (2005), pp. 320-408.
HАммоск, 1985 - B. D. Hammock, Regulation of juvenile hormone titer: degradation. In: G.A. Kerkut and L.I. Gilbert, Editors, Comprehensive Insect Physiology, Biochemistry and Pharmacology Vol. 7, Pergamon Press (1985), pp. 431-472.

Hinton and Hammock, 2003 - A. C. Hinton and B. D. Hammock, Juvenile hormone esterase (JHE) from Tenebrio molitor: full-length cDNA, in vitro expression, and characterization of the recombinant protein, Insect Biochem. Mol. Biol. 33 (2003), pp. 477-487.

Jobi ET AL., 2004 - G. Jobb, A. von Haeseler, and K. Strimmer, TREEFINDER: a powerful graphical analysis environment for molecular phylogenetics, BMC Evol. Biol. 28 (2004), pp. 4-18.

Kumar et al., 2004 - S. Kumar, K. Tamura, and M. Nei, MEGA3: integrated software for molecular evolutionary genetics and sequence alignment, Briefings Bioinfomatics 5 (2004), pp. 150-163.

Merlin ET AL., 2007 - C. Merlin, G. Rosell, G. Carot-Sans, M.-C. Francois, F. Bozzolan, J. Pelletier, E. Jacquin-Joly, A. Guerrero, and M. Maibeche-Coisne, Antennal esterase cDNAs from two pest moths, Spodoptera littoralis and Sesamia nonagrioides, potentially involved in odourant degradation, Insect Mol. Biol. 16 (2007), pp. 73-81.

MunYiri AND IshiKawa, 2007 - F. N. Munyiri and Y. Ishikawa, Molecular cloning and developmental expression of the gene encoding juvenile hormone esterase in the yellow-spotted longicorn beetle, Psacothea hilaris, Insect Biochem. Mol. Biol. 37 (2007), pp. 497-505.

OAKeshott et AL., 2005 - J. G. Oakeshott, C. M. Claudianos, R. D. Newcomb, and R. J. Russell, Biochemical genetics and genomics of insect esterases. In: L. I. Gilbert, K. Iatrou and S. S. Gill, Editors, Comprehensive Molecular Insect Science-Pharmacology vol. 5, Elsevier, Oxford (2005), pp. 309-381. Abstract

SAmbrook ET AL., 1989 - J. Sambrook, E. F. Fritsch, and E. F. Maniatis, Molecular Cloning, a Laboratory Manual (second ed.), Cold Spring Harbor Laboratory Press, Cold Spring Harbor, NY (1989).

Venkataraman et al., 1994 - V. Venkataraman, P. J. O’Mahony, M. Manzcak, and G. Jones, Regulation of juvenile hormone esterase gene transcription by juvenile hormone, Dev. Genet. 15 (5) (1994), pp. 391-400.

Wogulis $E T A L ., 2006$ - M. Wogulis, C. E. Wheelock, S. G. Kamita, A. C. Hinton, P. A. Whetstone, B. D. Hammock, and D. K. Wilson, Structural studies of a potent insect maturation inhibitor bound to the juvenile hormone esterase of Manduca sexta, Biochemistry 45 (13) (2006), pp. 4045-4057.

ZERA, 2006 - A. J. Zera, Evolutionary genetics of juvenile hormone and ecdysteroid regulation in Gryllus: a case study in the microevolution of endocrine regulation, Comp. Biochem. Physiol. A: Mol. Integr. Physiol. 144 (3) (2006), pp. 365-379.

Zera And Zhang, 1995 - A. J. Zera and C. Zhang, Evolutionary endocrinology of juvenile hormone esterase in Gryllus assimilis: direct and correlated responses to selection, Genetics 141 (3) (1995), pp. $1125-1134$

Zera ET AL., 2002 - A. J. Zera, T. Sanger, J. Hanes, and L. Harshman, Purification and characterization of hemolymph juvenile hormone esterase from the cricket, Gryllus assimilis, Arch. Insect Biochem. Physiol. 49 (2002), pp. 41-55.

Zera ET AL., 2007 - A. J. Zera, L.G. Harshman, and T. D. Williams, Evolutionary endocrinology: the developing synthesis between endocrinology and evolutionary genetics, Annu. Rev. Ecol. Evol. Syst. 38 (2007), pp. 793-817. 